The following winter this battery was taken ts St. Petersburg, and Prof. Lenz demonstrated its action to a distinguished auditory, formed of members of the Imperial family and generals of the army. It was during this lecture that M. Lewitski obtained a photograph of the professor. A positive of this portrait was presented by M. Lermantoff to the Russian Physical Society at the séance on December 14, 1880. It is by no means a poor photograph, but full of detail in the shadows and half tints.

IN a recent report of the Berlin Physical Society (p. 95) we referred to some valuable observations by Dr. Kœnig with Prof. Helmholtz's new instrument, called the leutoscope. We observe that a detailed account (with illustration) of the instrument and of the results obtained with it, appears in Wiedemann's Annalen, Nos. 12 and 13 of last year.

Prof. F. W. Putnam has concluded a very successful course of lectures at the Peabody Museum, Boston, on some of the most interesting of American antiquities. The Boston Evening Transcript in an article on the lectures says:-"It is to be hoped that the curator will not again be retarded in his work from the want of means for its prosecntion, when he bas shown, as he has in this course of lectures, how much can be done at comparatively little expense under proper methods of research. As he said in his lecture, what is to be done must be done at once, and it would be a great pity to have the opportunities now open to him lost to science. The ancient city known to the present inhabitants of the Little Miami Valley, thirty-five miles east of Cincinnati, as 'Fort Ancient,' would be worth to American scholars for study as much as any of the old Greek cities that have been so thoroughly dug over by European explorers and students. Certainly American scholars should lead in American archæology and ethnology. The restoration or preservation of these wonderful remains of a comparatively enlightened prehistoric American people would be a glorious monument for any American Institution of learning and science."

SHocks of earthquake have been felt in the province of Murcia, in Spain. Seven shocks occurred at Archena on the IIth inst. Shocks have also been felt at Fortuna, Muta, Ricotel and other towns in Murcia. Eleven distinct shocks were felt on Tuesday morning at Archena, between the hours of three and six. Some lasted fifteen, and others lasted two seconds. An earthquake of a few seconds duration was experienced at Kultorp, near Kalmar, in Sweden, at 8.50 p.w. on the 12 th inst. A slight shock of earthquake was felt at Monmonth at five o'clock on Tuesday evening, accompanied by a light, rushing noise. The wave seemed to pass from south-east to north-west.

A REMARKABLE discovery of the elder Runic inscriptions has just been made in Ryfylke in Norway. The characters have been made on a stone, the arrival of which in Christiania is awaited with great interest by savants.

THe French Minister of Postal Telegraphy in France has established at the central office a special course of lectures on Wheatstone's automatic apparatus, to which sixteen competent operators, from different parts of the country, have been admitted. 'T he course of lectures and experiments has lasted two months. The pupils are now passing an examination, and a special certificate will be issued to the successful candidates, which will greatly help them in their future promotion in the postal telegraphic service.

THE Parc Montceau, placed in one of the most fashionable parts of Paris is now lighted by Jablochkoff candles with success.

Admiral Mouchez has issued his invitation for the Soirées de l'Observatoire, at which as usual will be exhibited all the scientific novelties of the year.
M. Chevreul has been unanimously nominated once more President of the French Société Nationale d'Agriculture.

IT is expected that the French Government will take in hand the celebration of the centenary of the discovery of balloons. The two committees which had been formed by several aeronautical societies have been amalgamated, and $\mathbf{M}$, Gaston Tissandier has been appointed president. The scheme of an international exhibition for balloons and instruments used in aërial investigations has been adopted by $M$. Herrisson, the Minister of Public Works, and will be carried into effect by $M$. Armengaud Jeane, the well-known civil engineer.

IN his speech on laying down his office, previous to being admitted Vice-Chancellor for the year $188_{3}$, Dr. Porter, Master of Peterhouse, Cambridge, referred to the endowments of the new Professorships of Physiology and Patholugy, increased grants to the museums and lecture-rooms, and a chemical laboratory on an adequate scale, as among the more urgent claims on the new funds available to the University.

Prof. FrISBY writes from the U.S. Naval Observatory, Washington, that in the circular he lately sent (NATURE, vol. xxvii. p. 226), giving elliptic orbit of great comet, $\phi=89^{\circ} 7^{\prime} 42^{\prime \prime} \cdot 70$ should be $\phi=89^{\circ} \mathrm{I}^{\prime} 42^{\prime \prime} \cdot 70$.

THE additions to the Zoological Society's Gardens during the past week include a Bonnet Monkey (Macacus radiatus of) from India, presented by Mr. C. James; a Common Otter (Lutra vulgaris), British, presented by Mr. E. P. Squarey; a Blacknecked Hare (Lepus nigricollis o) from Ceylon, presented by Mr. W. Bowden Smith; an Indian Antelope (Antilope cervicapra) from India, presented by Capt. R. Brooke Hunt; a Bohor Antelope (Cervicapra bohor $\&$ ) from India, presented by Mr. W. J. Evelyn; a Black-backed Jackal (Canis mesomelas) from South Africa, presented by Mr. J. S. Crow; a Larger Hill Mynah (Gracula intermedia) from India, presented by Mrs. M. R. Manuel ; three Passenger Pigeons (Ectopistes migratorius) from North America, presented by Mr. F. J. Thompson; a Horned Lizard (Phrynosoma - ) fron California, presented by Mr. Martin R. de Selincourt; a Common Adder (Vipera berus), British, presented by Mr. J. Harris ; an Indian Black Cuckoo (Eudynamys orientalis) from India, purchased; an Axis Deer (Cervus axis of), born in the Gardens.

\section{APPROXIMATIVE PHOTOMETRIC MEASURE- MENTS OF SUN, MOON, CLOUDY SKY, AND ELECTRIC AND OTHER ARTIFICIAL LIGHTS ${ }^{1}$}

SIR WILLIAM THOMSON pointed out that the light and heat perceived in the radiations from hot bodies were but the different modes in which the energy of vibration induced by the heat was conveyed to our consciousness. A hot kettle; red-hot iron ; incandescent iron, platinum, or carbon, the incandescence in the electric arc, all radiate energy in the same manner, and according as it is perceived through the sense of sight, by its organ the eye, or by the sense of heat, ${ }^{2}$ we speak of it as light or heat. When the period of vibration is longer than one four-hundred. million-millionth of a second, the radiation can only be per ceived by the sense of heat; when the period of vibration i.

I Abstract of !ecture at the Glasgow Philosophical-Society, by Sir William Thoms Jn, F.R.S.

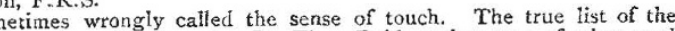
censes, first given, I believe, by Dr. Thos. Reid, makes tw 0 of what used to be called the senie of touch, so that, in itead of the still too common wrong-reckoning of five senses, we have six, as follows :-

$$
\begin{array}{rr}
\text { Sense of Force. } \\
\text { ", } & \text { Heat. } \\
\text { " } & \text { Sound. } \\
\text { Light. } & \text { Taste. } \\
\text { " } & \text { Smell. }
\end{array}
$$


shorter than one four-hundred-million-millionth of a second, and longer than one eight-hundred-million-millionth of a second, the radiation is perceived as light, by the eye.

Pouillet, from a series of experiments, deduced a value of the energy radiated by the sun, equal in British units to about 86 foot-pounds per second per square foot at the earth's surface, or about I horse-power to every $6 \frac{1}{2}$ square feet of the earth's surface. We may estimate from this the value of the solar radiation at the surface of the sun. The sun is merely an incandescent molten mass losing beat by radiation, and surrounded by an atmosphere of incandescent vapour, so that the radiant energy really comes out from any square foot or square mile of the sun's surface, as from a pit of luminous fluid which we cannot distinguish as either gaseous or liquid. Take, however, instead of the sun, an ideal radiating surface of a solid globe of 440,000 miles radius. The distance of the earth being taken as 93 million miles, the radius of the sun is equal to, say in round numbers, one two-hundredth of the earth's distance, hence the area at the earth's distance corresfonding to one square foot of the sun's surface, is equal to 40,000 square feet. The radiation on this surface is $(40,000 \times 86$, or $) 3,440,000$ foot-pounds, which is therefore the amount of radiation from each square foot of the sun's surface. This amounts to about 7000 horse-power, which, according to our brain-wasting British measure, we must divide by $\mathrm{I} 44$, if we wish to know the radiation per square inch of the sun's surface, which we thus find to be 50 horse-power.

The normal current through a Swan lamp giving a 20 -candle light is equal to I.4 amperes with a potential of 40 to 45 volts. Hence the activity of the electric working in the filament is $6 \mathbf{r} \cdot 6$ amfere-volts or Watts (according to Dr. Siemens' happy designation of the name of Watt, to represent the unit of activity constituted by the amfere-volt). To reduce this to horse-power we must divide by 746 , and we thus find about I-I 2 th of a horse-power for the electric activity in a Swan lamp. The filament is $3 \frac{1}{2}$ inches long, and or of an inch in diameter of circular section; the area of the surface is thus $I-9$ th of a square inch, and therefore the activity is at the rate of $3-4^{\text {ths }}$ of a horse-power per square inch. Hence the activity of the sun's radiation is about sixty-seven times greater than that of a Swan lamp per equal area, when incandesced to 240 candles per horsepower.

In this country the standard light to which photometric measurements are referred is that obtained from what is known as a standard candle. Latterly, however, objections have been raised against its accuracy. It has been said that differences of as much as 14 per cent. have been found in the intensity of the li hht given by different standard candles, and that serious differences have been observed in the intensity of the light from different parts of the same candle in the course of its burning. The Carcel lamp, the standard in use in France, has been regarded as the only reliable standard. It is, no doubt, very reliable and accurate in its indications, but it should be remembered that its accuracy is greatly owing to the careful method and the laborious precautions taken to secure accuracy. If something akin to the precautions applied to the Carcel lamp by Regnault and Dumas were applied to the production and use of the standard candle, there is little doubt but that sufficient accuracy for most practical purposes could also be obtained with it; probably as good results as are already obtained by the use of the Carcel lamp.

At the Conference on Electrical Units which met in Paris lately, a suggestion was made to use as a standard for photometric measurements the incandescence of melting platinum, and very interesting results and methods in connection with the proposal were presented to the meeting. According to experiments by Mr. Violle, which M. Dumas reported to the Conference, a square centimetre of liquid platinum at the melting temperature gives of yellow light seven, and of violet twelve times the quantities of the same colours given by a Carcel lamp. The apparent area of the Swan filament, bein $s$ one-ninth of a square incb, is $\cdot 23$ of a square centimetre, and when incandesced to 20 candles mu:t be about as bright as the melted platinum of Mr. Violle's experiment, as the 7 carcels of yellow and I 2 of violet must correspond to something like ro carcels or 85 candles, in the ordinary estimation of illumination by our eyes. The tint of Mr. Violle's glowing platinum cannot be very different from that of the ordinary Swan lamp incandesced to its " 20 candles." Thus both, as to tint, and brightness, it appears that melted platinum at its freezing temperature is nearly the same as a carbon filament in vacuum incandesced to 240 candles per horse-power.
For approximative photometric meacurements the most convenient method is certainly that of Rumford, by a comparison of the shadows cast by the sources of light on a white surface. The apparatus necessary are only a piece of white paper, a small cylindrical body such as a pencil, and a means of measuring distances. Ordinary healthy eyes are usually quite consistent in estimating the strength of shadows, even when the shadows examined are of different colours, and with a reasonable amount of care photometric measurements by this method may be obtained within 2 or 3 per cent . of accuracy. The difference in the colours of the shadows is of course due to each shadow being illuminated by the other light.

Arago has compared the luminous intensity of the sun with that of a candle, and estimates it as equal to about 15,000 times that of a candle flame.

Seidel, as Sir W. Thomson had been informed by Helmholtz, estimated the luminous intensity of the moon as about equal to that of grayish basalt or sandstone. An experiment on sunlight made in Glasgow on the 8th of this month (since this paper was read), compared with an observation on moonlight, which he made at York during the meeting of the British Ascociation there in 1881 , had led him to conclude that the surface of the moon radiates something not enormously different from onequarter of the light incident upon it. It would be exactly this if the transparency of the Glasgow noon atmosphere of December 8 , I 882, had been exactly equal to that of the York midnight atmosphere of September, 188I, referred to below, for the respective altitudes of the sun and moon on the two occasions. The observation on moonlight referred to above showed the mocnlight at the time and place of the observation (at York early in September, $188 \mathrm{I}$, about midnight, near the time of full moon) to he equal to that of a candle at a distance of 230 centi. metres. The moon's distance $\left(3.8 \times 10^{10} \mathrm{~cm}\right.$.) is $1.65 \times 10^{8}$ times the distance of the candle. Hence, ignoring for a moment the loss of moonlight in transmission through the earth's atmosphere, we find $\left(165 \times 10^{8}\right)^{2}$, or 27 thousand million million as the number of candles that must be spread cver the moon's earthward hemisphere painted black, to send us as much light as we receive from her. Probably about one and a balf times as many candles, or say forty thousand million million would be required, because the absorption by the earth's atmosphere may have stopped about one-third of the light from reaching the place where the observation was made. The moon's diameter is $3.5 \times 10^{8}$ centimetres, and therefore half the area of her surface is $19 \times 10^{16}$ square centimetres, which is nearly five times forty thousand million milion. Thus it appears that if the hemisphere of the moon facing the earth were painted black and covered with candles standing packed in square order touching one another (being say one candle to every five square centimetres of surface), all burning normally, the light received at the earth would he about the same in quantity as estimated by our eyes, as it really is. It would have very much the same tint and general appearance as an ordinary theatrical moon, except that it would be brightest at the rim and continucusly less bright from the rim to the centre of the circle where the brightness would be least.

The luminous intensity of a clcudy sky he found about roa.m. one day in York during the meeting of the British Association to be such that light from it thrrugh an aperture of one square inch area was equal to about one candle. The colour of its shadow compared with that from a candle was as deep buff yellow to azure blue, the former shadow heing illuminated by the candle alone, the latter by the light coming through the inch hole in the window sbutter.

The experiment on sunlight of last Friday (December 8) showed, at I o'clock on that day, the sunlight reaching his house in the University to be of such brilliancy that the amount of it coming through a pinhole in a piece of raper of 09 of a centimetre diameter produced an illumination equal to that of 126 candles. This is 6.3 times the 20-candle Swan light, of which the apparent area of incandescent surface is 23 of a
square centin etre, or 3.8 times the area of the pin-hole. Hence the : un's surface as seen through the atmosphere at the time and place of observation was 24 times as bright as the Swan carbon when incandesced to 240 candles per horse-power. By cutting a piece of paper of such shape and size as just to eclipse the flame of the candle and measuring the area of the piece of paper, he found about $2.7 \mathrm{sq}$. centims. as the corresponding area of the flame. This is 420 times the area of the pin-hole, and therefore the intensity of the light from the sun's disc was equal to 
( $126 \times 420$ ) about 53,000 times that of a candle-flame. This is more than three times the value found by Arago for the intensity of the light from the sun's disc as compared with that from a candle-flame; so much for a Glasgow December sun !

The $09 \mathrm{~cm}$. diameter of the pin-hole, of the Glasgow observation, subtends, at 230 centimetres distance, an angle of $1 / 2556$ of a radian; which is 23.7 times the sun's diameter ( $r / 108$ of a radian). But at $230 \mathrm{~cm}$, distance the sunlight through the pinhole amounted to I26 times the York moonlight (which was I candle at $230 \mathrm{~cm}$. distance). Hence the Glasgow sunlight was $\left[\left(23^{7} 7\right)^{2} \times \mathbf{1 2 6}\right.$ times or $] 7 \mathbf{I}, 000$ times the York moonlight. We cannot therefore be very far wrong in estimating the light of full moon as about one-seventy-thousandth of the sunlight, anywhere on the earth. This, however, is a comparison which, because of the probably close agreement of the tints of the two lights, can probably be made with minute accuracy: and we must therefore not be satisfied with so very rough an approximation to the ratio as this 70,000 . A lime light, or magnesium light, or electric arc-light, carefully made and remade with very exactly equal brilliance, for each separate observation of sunlight and moonlight, might be used for intermediary.

\section{THE HYPOTHESIS OF ACCELERATED DE \\ VELOPMENT BY PRIMOGENITURE, AND ITS PLACE IN THE THEORY OF EVOLU-} TION

I $N$ our days the student of the biological sciences may look forward towards his life-task with sincere gratitude. Gratitude not only for what has already been achieved, and for the ends that have been attained in this domain, but more especially for all that which the future promises, since the sage whose mortal remains were lately deposited in Westminster Abbey has thrown the light of his genius over regions which hitherto were shrouded in deepest obscurity and has opened new vistas on old problems, of which man has been seeking the solution for many thousands of years.

it is to him we have to give thanks that the dawn of a new life has commenced for those sciences; to him, moreover, we owe it that the twilight has only lasted a short time, and that the full light of day has shone so soon upon an extensive field. And if by this light we perceive numerous new problems, the existence of which was not even dreamt of before, and which cover the field of our work as far as the horizon reaches, still we notice that their shapes have obtained definite outlines. In future they may serve as milestones on our way onwards, before, when we were still groping in the dark, they were as many stumbling-block; which prevented us from advancing.

If to-day $I$ call before your mind the inage of this great reformer, it is not to give you an eulogy of Darwin, whose sudden death some months ago has filled with grief the whole civilised world. He is before my mind, becau e I belong to the generation whose youth coincides with that of the "Origin of Species;" a generation deeply filled with gratitude towards this great master. A gratitude bursting forth with doubled intensity in him who enters upon a career in which he will have ample opportunity to continue work in that field of science to which he has become more and more attached through the inspiring influence of Darwin.

It is not only by the contents of his work that Darwin tıkes hold of us, it is also his personal character which leaves such a forcible impression. The history of his life, his method of work, his amiable individuality, have excited our enthusiasm over and again, and always in an increasing measure. Similar to other grand figures in the history of the world, who by their life and their example have perhaps wrought more than by their teaching - which at the hands of les; eminent adepts soon took a dogmatic, i.e. a degenerate shape-this reformer of biological science has left behind him a remembrance which will be kept and transmitted by his followers with quite as much care and piety as the writings he has left.

What strikes us most and all at first in everything emanating from him is his passionate honesty, ${ }^{2}$ which bas already become proverbial. Never did he pass over in silence, in the interest of his argument, a point which might eventually appear to be in favour of the oppo:ite plea. In the enumeration and refutation of such points he was always quite as careful as in the collection ${ }^{2}$ By Prof. A. A. W. Hubrecht. Inaugural Address delivered in the University of Utrecht. September, 1882

2 Cf. Huxley, NATURe, May, 1882. of positive proofs. He was never biassed, unless biassed in the good sense of the term, i.e. enabled, when once he was of opinion that it was necessary to choose a decided side with respect to any dubious point, to devote to the careful consideration of this point not only hours, but if necessary months and years of his life, - - months and years of daily returning observations concerning what appeared to be unimportant facts, whicb, however, when they were afterwards brought together, permitted him to draw highly important conclusions.

Unlimited veracity and undaunted patience, two principal requirements of the true naturalist, thus found their most perfect incarnation in Darwin, and with these two for his guides, he brought together, from far and near, building stones for the com. pletion of the grand structure which his mind had conceived. The quarries from whence he excavated those building stones were very different from those to which the scribes in biological science habitually resorted. It must be understood that since the appearance of Cuvier's “ Le Règne Animal distribué d'après son Urganisation," a reaction had sprung up against descriptive zoology which in many cases went further than Cuvier himself would ever have acknowledged. The numerous volumes of his excellent "Histoire naturelle des Poissons" furnish ample proof that Cuvier had always endeavoured to combine careful description of the species and conscientious sifting of all the material concerning its life history, its geographical distribution, and its synonymy with the study of the comparative anatomy of the group to which it belonged. Several of his followers have, however, concluded that since researches upon the internal organisation of so many classes of animals allowed him to make most important deductions, it was from similar researches only that anything could be expected for the future. Their ambitious aspirations could not manage to forget that a combined investiga. tion by Cuvier and Geoffroy St. Hilaire was once described by one of the two in the following words:- "Nous ne déjêunions jamais sans avoir fait une découverte."

And so $\approx$ period was opened up in which our knowledge of the internal organisation of animals was not only increased on all sides and firmly based upon fucts by zealous workers, but in which this knowledge was gradually pushed into the foreground as the pre-eminent, as the only true zoology. The careful study of the species and its life history was left with a smile and a shrug of the shoulders to dilettanti and museum zoologists. In order further, to indicate how the results of researches of these men were looked upon as popular and unimportant, this new school invented the well-sounding name of "scientific zuology."

The eminent researches of von Siebold on parthenogenesis and on the freshwater fishes of Germany; Kölliker's important monograph of the Pennatulids, \&c., show that even its founders were subject to impulses which drove them back into this very field, or rather that it was not they, but their less gifted followers from whom the cuntemptuous meaning which that combinati on of words gradually attained has emanated.

Thus for a certain lapse of time the wind blew from a different quarter, and attempts have repeatedly been made to call into life classifications which were based upon certain points in the internal organi=ation, points which were considered to be of the more importance the le,s they were visible. Fortunately the great masters to whom we owe comparative anatomy, and who have made it such as we know it in the present day, have not joined in this movement. Johannes Müller's "System der Plagiostomen" stands side by side with his "Comparative Anatomy of the Myxinoids," showing that this one-sided exaggeration would never have been encouraged by himself. Gegenbaur, Huxley, \&c., have similarly kept aloof from the "scientific zoologists" in the stricter sense, whose narrow-minded doctrines are still pullula'ing, be it in a somewhat modified form. At the present day it is not so much the internal organisation which forms the shibboleth by which entrance is obtained to the holy circle of self-styled orthodox zoologists, but now it is the history of development, embryology, that gives the pass-word. This important branch of biological science has made gigantic strides of late; it counted in its foremost ranks, among the most promising and large-minded, the man whom a cruel fate had doomed to find his deat : in the Alps of Switzerland, the talented Balfour. He never overvalued in a petty way the labours of the select batallion of which he was one of the leaders. In the rear of this army, however, voices are heard claiming infallibility for embryology, and the splendid generalisation: "the development of the individual is a repetition on a reduced scale of the development of the race," must often serve to hide unripe 